\title{
Resistência a antimicrobianos em enterococos isolados de amostras de fezes de suínos*
}

\author{
Antimicrobial resistance analysis among enterococci isolated from pig feces \\ Adriana de Abreu Corrêa', Daiane Bopp Fuentefria ${ }^{2}$ \& Gertrudes Corção ${ }^{1,2}$
}

\begin{abstract}
RESUMO
Nos últimos anos, os enterococos têm sido considerados importantes patógenos nosocomiais associados a infecções de dif́́cil tratamento, devido a multiresistência a antimicrobianos. Freqüentes ocorrências de enterococos multiresistentes têm sido reportadas em amostras de origem animal, as quais atuariam como reservatórios destas linhagens e contribuiriam para disseminação desta resistência através da cadeia alimentar. O presente estudo teve como objetivo comparar a resistência a 11 antimicrobianos em 85 isolados de Enterococcus provenientes de fezes de suínos arraçoados e em 88 isolados provenientes de suínos não arraçoados. No primeiro grupo foram isolados E. faecalis (21), E. faecium (18), E. hirae (9), E. durans (30) e E. mundtii (7) e no segundo grupo, E. faecalis (27), E. faecium (17), E. durans (1) e E. mundtii (43). Entre os Enterococcus spp. isolados de amostras de fezes de suínos arraçoados, foI observada uma maior porcentagem de cepas resistentes e a multiresistência entre estes isolados foi de 3 a 6 antimicrobianos, enquanto que entre os não arraçoados foi de 3 a 4 antimicrobianos. As diferenças na predominância de espécies e perfil de resistência entre as diferentes amostras pode estar relacionado à dieta alimentar dos animais.
\end{abstract}

Descritores: Enterococcus, resistência, multirresistência, antimicrobianos, cadeia alimentar.

\section{ABSTRACT}

In the last years, enterococci have been considered as important nosocomial pathogens, associated with infections difficult to treat due to their resistance to several antimicrobials. Frequent occurrences of multiresistant enterococci have been reported among animal origin samples, which could act as reservoir of these resistant strains and contribute to the spread of antibiotic resistance through the food chain. The aim of the present study was to compare the antimicrobial resistance against 11 antibiotics on 85 isolates of Enterococcus isolated from pig feces, fed with suplemented feed, and on 88 isolates from pig feces, fed with nonsuplemented feed. In the first group, isolates of E. faecalis (21), E. faecium (18), E. hirae (9), E. durans (30) and E. mundtii (7) were isolated and in the second group, E. faecalis (27), E. faecium (17), E. durans (1) and $E$. mundtii (43) were found. Among the Enterococcus spp. isolated from the suplemented feed pig, higher percentages of resistance were observed and multiple resistance was between three and six antibiotics, while among the nonsuplemented pigs, it was between three and four antibiotics. The differences on the species predominance and antibiotic resistance pattern among the samples can be related to the animal diet.

Key words: Enterococcus, resistance, multiple resistance, antimicrobials, food chain. 


\section{INTRODUÇÃO}

O gênero Enterococcus pode ser encontrado em diversos ambientes, como solo, água, plantas e animais, é capaz de sobreviver em ambientes salinos, em concentrações de 6,5\% de $\mathrm{NaCl}$, em pH 9,6 e em temperaturas que variam de $10^{\circ} \mathrm{C}$ a $45^{\circ} \mathrm{C}[6,9]$. A causa específica para o interesse em patogenias causadas por Enterococcus é seu amplo espectro de resistência a antimicrobianos e sua participação na disseminação desta resistência na cadeia alimentar [3,4,9].

A transferência de genes de resistência já foi identificada entre cepas de E. faecalis em águas de tratamento de esgoto, aumentando a possibilidade de se inferir sobre o papel de cepas ambientais na disseminação destes genes [6,7]. Além disso, Enterococcus sp. resistentes têm sido freqüentemente observados em animais de corte, sugerindo que estes possam ser reservatórios de linhagens resistentes e consequentemente de genes de resistência, os quais podem ser transferidos para humanos através da cadeia alimentar [1, $4,15,16]$.

A partir desta idéia, o presente trabalho foi desenvolvido com a finalidade de comparar a resistência e multirresistência a antimicrobianos entre cepas de Enterococcus sp. provenientes de amostras de suínos arraçoados e de suínos não arraçoados, uma vez que o uso de ração associada a antimicrobianos pode acarretar o aumento de cepas resistentes no meio ambiente.

\section{MATERIAIS E MÉTODOS}

\section{Amostras}

Foram coletadas quatro amostras de fezes de suínos arraçoados, provenientes de uma granja localizada na região do Vale do Taquari, e cinco amostras de fezes de suínos não arraçoados em criações domésticas, localizadas na região rural de Porto Alegre. Estas criações fazem parte do programa PRRO via Suinocultura do Departamento Municipal de Lixo Urbano da Prefeitura de Porto Alegre (DMLU-PMPA) com criadores de suínos desta região, no qual o DLMU fornece aos criadores restos de alimento coletados nos restaurantes de Porto Alegre.

\section{Isolamento e identificação dos Enterococcus spp.}

As amostras de fezes (25 gramas) foram ressuspendidas em $250 \mathrm{~mL}$ de solução salina ( $0,9 \%)$ e semeadas em Caldo Azida ${ }^{1}$. Após 24h de incubação, de cada tubo com crescimento bacteriano, foram reti- radas nove alíquotas e inoculadas em nove placas de ágar $\mathrm{KF}^{2}$, as quais foram incubadas por $48 \mathrm{~h}$ a $37^{\circ} \mathrm{C}$. As colônias amareladas, esbranquiçadas e punctiformes foram testadas para coloração de Gram e as que apresentaram cocos Gram positivos foram inoculadas em ágar PSE por $48 \mathrm{~h}$ a $37^{\circ} \mathrm{C}$. As colônias de coloração marrom, foram retiradas e armazenadas em ágar inclinado, para posterior identificação de gênero e espécie conforme Facklam \& Collins [2].

Para confirmação do gênero Enterococcus, foram realizadas quatro provas bioquímicas: produção de catalase, crescimento em $\mathrm{NaCl}$ 6,5\%, crescimento a $45^{\circ} \mathrm{C}$ e produção de pirrolidonil arilamidase $\left(\mathrm{PYR}^{3}\right)$. Para identificação das espécies, foram feitos: teste de fermentação de carboidratos ${ }^{1}$ (arabinose, rafinose, manitol, xilose e sorbitol), utilização de piruvato $1 \% 4$, produção de pigmento amarelo, motilidade e descarboxilação da arginina ${ }^{1}$. As cepas E. faecalis ATCC 29212, E. hirae ATCC 10541, Escherichia coli ATCC 25922 e Enterobacter aerogenes ATCC 13048, foram utilizadas como controle positivo nos testes bioquímicos.

\section{Teste de suscetibilidade a antimicrobianos}

Os isolados identificados foram testados quanto a suscetibilidade a antimicrobianos pelo método de difusão em ágar, conforme metodologia NCCLS [12], utilizando como controle, a cepa Enterococcus faecalis ATCC 29212. Foram testados onze antimicrobianos ${ }^{5}$ : cefalotina $(30 \mathrm{mcg})$, eritromicina $(15 \mathrm{mcg})$, vancomicina $(30 \mathrm{mcg})$, estreptomicina $(300 \mathrm{mcg})$, rifampicina (30mcg), tetraciclina $(30 \mathrm{mcg})$, cloranfenicol $(30 \mathrm{mcg})$, cefoxitina $(30 \mathrm{mcg})$, gentamicina $(120 \mathrm{mcg})$, amicacina (30 mcg) e ampicilina (10mcg). A interpretação dos halos de inibição foi realizada conforme normas do NCCLS [12] e os isolados de Enterococcus classificados como resistentes ou sensíveis.

\section{RESULTADOS}

No presente estudo foram encontrados 85 isolados distribuídas em cinco espécies do gênero Enterococcus, a partir das amostras de fezes dos suínos arraçoados e 88 isolados, distribuídos em quatro espécies, das amostras de fezes de suínos não arraçoados (Tabela 1).

Nos testes de suscetibilidade a antimicrobianos, foram obtidos perfis diferentes entre os dois grupos testados (Tabela 2). A resistência à ampicilina, rifampicina, vancomicina e gentamicina não foi observada em ambos os grupos de isolados. Entre os isolados de suínos 


\begin{tabular}{|c|c|c|c|c|c|}
\hline \multirow{2}{*}{ Origem da amostra } & \multicolumn{5}{|c|}{ Espécies identificadas } \\
\hline & E. faecalis & E.faecium & E. hirae & E. durans & E. mundtii \\
\hline $\begin{array}{l}\text { Fezes de suínos não } \\
\text { arraçoados }(n=88)\end{array}$ & 27 & 17 & - & 1 & 43 \\
\hline $\begin{array}{l}\text { Fezes de suínos } \\
\text { arraçoados }(n=85)\end{array}$ & 21 & 18 & 9 & 30 & 7 \\
\hline
\end{tabular}

arraçoados, todos foram resistentes à tetraciclina e entre os isolados de fezes de suínos não arraçoados, todos apresentaram-se sensíveis a estreptomicina, cloranfenicol e tetraciclina.

$\mathrm{Na}$ análise de multirresistência em suínos arraçoados, todas as espécies, com exceção de $E$. durans, foram multirresistentes a seis antimicrobianos (Figura 1A). Nas cepas de fezes de suínos não-arraçoados, a multirresistência foi baixa, sendo máxima na espécie $E$. mundtii, multirresistente para até 4 antimicrobianos (Figura 1B).

\section{DISCUSSÃO}

Os resultados diferenciados para o número de isolados de cada espécie estão relacionados às distintas dietas consumidas pelos suínos. Nas duas amostras foram observados $E$. faecalis e E. faecium, todavia não foram as espécies predominantes, como encontrado em diversos trabalhos $[1,7,9,13]$. As espécies $E$. faecalis e E. faecium adquirem mais facilmente resistência, portanto são mais prevalentes nas fezes de suínos arraçoados [1]. As espécies E. durans e E. hirae são encontradas em suínos $[5,10]$, todavia não
Tabela 2. Resistência a antimicrobianos para os isolados de Enterococcus spp. provenientes de amostras de fezes de suínos arraçoados e não arraçoados.

\begin{tabular}{lcc}
\hline $\begin{array}{c}\text { Antimicrobianos } \\
\text { testados }\end{array}$ & $\begin{array}{c}\text { Isolados de suínos } \\
\text { arraçoados } \\
(\mathbf{n}=\mathbf{8 5})\end{array}$ & $\begin{array}{c}\text { Isolados de suínos } \\
\text { não arraçoados } \\
\text { (n = 88) }\end{array}$ \\
\hline Cefoxitina & $49,50 \%$ & $69,30 \%$ \\
Cefalotina & $64,50 \%$ & $34,00 \%$ \\
Cloranfenicol & $2,10 \%$ & $0 \%$ \\
Tetraciclina & $100 \%$ & $0 \%$ \\
Amicacina & $97,80 \%$ & $6,80 \%$ \\
Ampicilina & $0 \%$ & $0 \%$ \\
Rifampicina & $0 \%$ & $0 \%$ \\
Vancomicina & $0 \%$ & $0 \%$ \\
Eritromicina & $98,90 \%$ & $36,30 \%$ \\
Estreptomicina & $26,90 \%$ & $0 \%$ \\
Gentamicina & $0 \%$ & $0 \%$ \\
\hline
\end{tabular}

são predominantes neste tipo de amostra. A predominância de E. durans entre os isolados de fezes de suínos arraçoados do presente estudo, deve-se, provavelmente, a sua maior resistência aos antimicro-

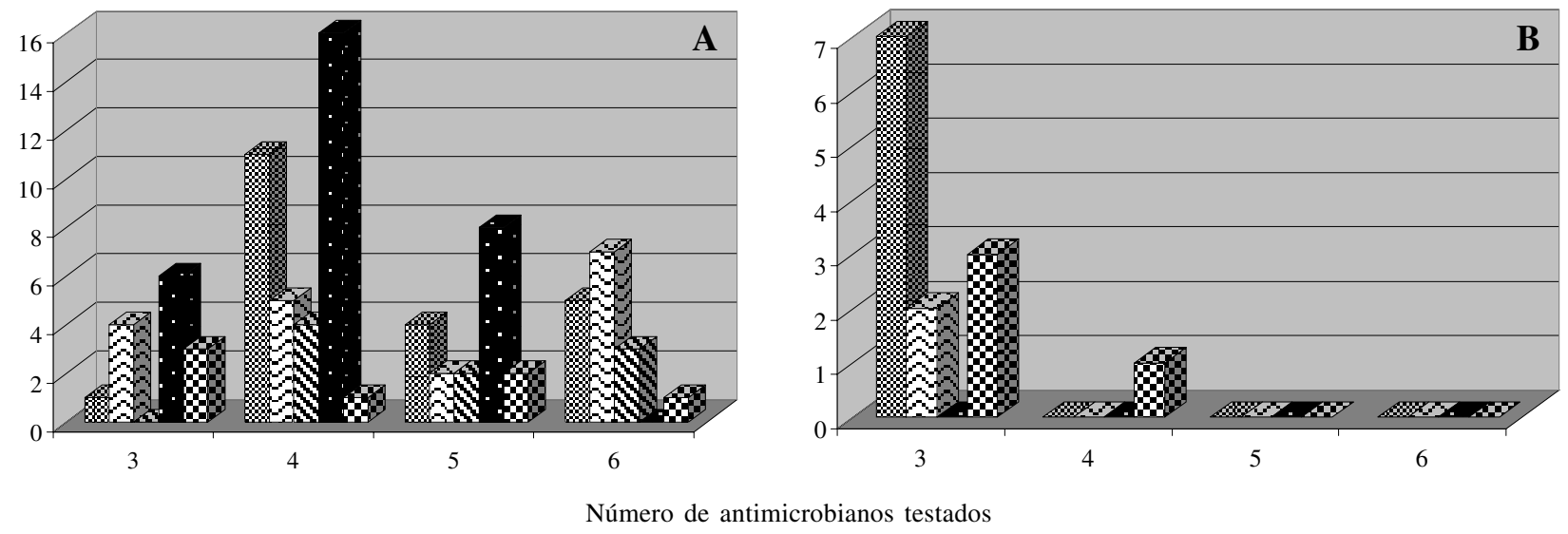

Figura 1. Perfil de multiresistência dos isolados de amostras de fezes de suínos arraçoados (A) e de suínos não arraçoados (B). No gráfico A estão indicados o número de isolados multiresistentes para as espécies E. faecalis, E. faecium, E. hirae, E. durans e E. mundtii, respectivamente, e no gráfico B, para as espécies E. faecalis, E. faecium, , E. durans e E. mundtii, respectivamente. 
bianos. E. mundtii foi menos predominante em fezes de suínos alimentados com ração suplementada do que entre os suínos alimentados com restos de comida. Como E. mundtii não é considerada uma espécie de origem fecal e sim de origem ambiental [8], a predominância destas cepas, pode estar relacionado com a metodologia de coleta das fezes, uma vez que neste grupo as amostras foram coletadas do chão das baias.

A resistência observada para cefoxitina, cefalotina e amicacina nos isolados das duas origens era esperada, pois o gênero Enterococcus apresenta resistência intrínseca a algumas cefalosporinas e a baixas concentrações de aminoglicosídeos [11]. A resistência para gentamicina e estreptomicina foi baixa devido às altas concentrações testadas, no entanto, estudos atuais indicam que algumas linhagens de Enterococcus têm adquirido resistência a altas concentrações de aminoglicosídeos [14]. Nenhum dos isolados mostrou-se resistente à vancomicina, este resultado é de especial interesse, uma vez que esta resistência tem sido muito observada entre cepas de E. faecium de alimentos de origem animal $[3,15]$ e de amostras clínicas e constitui um risco no tratamento de infecções nosocomiais em pacientes imunocomprometidos, causadas por esta espécie [9].

Tetraciclina e eritromicina são alguns dos antimicrobianos utilizado nas rações dos suínos arraçoados do presente estudo, provavelmente por isso uma grande porcentagem das cepas provenientes de tais amostras apresentaram-se resistentes a estes dois agentes. A multirresistência observada entre os isolados das duas origens apresentou diferenças significativas. $\mathrm{O}$ uso de antimicrobianos associados a rações gera uma pressão seletiva resultando em cepas multiresistentes, as quais podem ser liberadas no ambiente e contribuir para a disseminação destes genes [16].

O presente estudo contribuiu para o conhecimento da resistência entre Enterococcus spp. isolados de fezes de suínos, a qual é pouca estudada uma vez que esta bactéria não está vinculada a infecções neste hospedeiro. Todavia, existe uma preocupação cada vez maior com a participação destas espécies na disseminação de genes de resistência através da cadeia alimentar e no ambiente, sendo que muitas vezes o uso de antimicrobianos como promotores de crescimento pode contribuir para este fenômeno.

Agradecimentos. À Marcia Maria Nascimento de Almeida, Coordenadora do PPRRO via Suinocultura da Divisão $\mathrm{Mu}-$ nicipal de Limpeza Urbana, DMLU-PMPA e à Profa Marisa Ribeiro de Itapema Cardoso, Departamento de Medicina Veterinária Preventiva, Faculdade de Veterinária - UFRGS, pela colaboração na obtenção das amostras. À CAPES, pelo financiamento do projeto; ao CNPq, pelo financiamento das bolsas de Mestrado; e à Pró Reitoria de Pesquisa-UFRGS, pelo financiamento da bolsa de Iniciação Científica.

\section{NOTAS INFORMATIVAS}

${ }^{1}$ VETEC Química Fina Ltda, Rio de Janeiro/Brasil.

${ }^{2}$ Oxoid Ltd, Hampshire/England.

${ }^{3}$ PROBAC do Brasil Produtos bacteriológicos, São Paulo/ Brasil.

${ }^{4}$ SIGMA - ALDRICH, St Louis/USA.

${ }^{5} \mathrm{DME}$ - Diagnósticos Microbiológicos Especializados, Araçatuba/Brasil

\section{REFERÊNCIAS}

1 Aarestrup F.M., Hasman H., Jensen L.B., Moreno M., Herrero I.A., Dominguez L., Finn M. \& Franklin A. 2002. Antimicrobial Resistance among Enterococci from Pigs in Three European Countries. Applied and Environmental Microbiology. 68: 4127-4129.

2 Facklam R.R. \& Collins M.D. 1989. Identification of Enterococcus species isolated from human infections by a conventional test scheme. Journal of Clinical Microbiology. 27: 731-734.

3 Franz C.M.A.P., Muscholl-Silberhorn A.B., Yousif N.M., Vancanneyt M., Swings J. \& Holzapfel W.H. 2001. Incidende of Virulence Factors and Antibiotic Resistance among Enterococci Isolated from Food. Applied and Environmental Microbiology. 67: 4385-4389.

4 Giraffa G. 2002. Enterococci from foods. FEMS Microbiology Reviews. 26: 163-171.

5 Godfree A.F., Kay D. \& Wyer M.D. 1997. Faecal streptococci as indicator of faecal contamination in water. Journal of Applied Microbiology Symposium Supplement. 83: 110-119.

6 Harwood V.J., Whitlock J. \& Withington V. 2000. Classification of Antibiotic Resistance Patterns of Indicator Bacteria by Discriminant Analysis: Use in Predicting the Source of Fecal Contamnation in Subtropical Waters. Applied and Environmental Microbiology. 66: 3698-3704.

7 Junco M.T.T., Martin M.G. \& Toledo M.L.P. 2001. Identification and antibiotic resistance of faecal enterococci isolated from water samples. International Journal of Hygienic and Environmental Health. 203: 363-368. 
8 Klein G. 2003. Taxonomy, ecology and antibiotic resistance of enterococci from food and the gastro-intestinal tract. International Journal of Food Microbiology. 88: 123-131.

9 Kühn I., Iversen A., Burman L.G., Olsson-Liljequist B., Franklin A., Finn M., Aarestrup F., Seyfarth A.M., Blanch A.R., Vilanova X., Taylor, H., Caplin J., Moreno M.A., Dominguez L., Herrero I.A. \& Möllby R. 2003. Comparison of enteroccal populations in animals, humans and the environmental - a European study. International Journal of Food Microbiology. 88: 133-145.

10 Leclerc H., Devriese L.A. \& Mossel D.A.A. 1996. A Review: Taxonomical changes in intestinal (faecal) enterococci and streptococci: consequence on their use as indicators of faecal contamination in drinking water. Journal of Applied Bacteriology. 81: 459-466.

11 Morrison D., Woodford N. \& Cookson B. 1997. Enterococci as emerging pathogens of humans. Journal of Applied Microbiology Symposium Supplement. 83 (Suppl): 89-99

12 National Commitee For Clinical Laboratory Standards (NCCLS). 2000. Performance standards for antimicrobial susceptibity testing; Tenth Informational Supplement, M100-S10(M2). Wayne, Pa. 54p.

13 Pinto B., Pierotti R., Canale G. \& Reali D. 1999. Characterization of 'Faecal Streptococci' as indicators of faecal pollution and distribution in the environment. Letters in Applied Microbiology. 29: 258-263.

14 Rice E.W., Messer J.W., Johnson C.H. \& Reasoner D.J. 1995. Ocurrence of High-Level Aminoglycoside Resistance in Environmental Isolate of Enterococci. Applied and Environmental Microbiology. 61: 374-376.

15 Sakai Y., Tsukahara T. \& Ushida K. 2003. Isolation of vancomycin-resistant enterococci from pigs in Japan. Animal Science Journal. 74: 521-523.

16 Sengeløv G., Sørensen B.H. \& Aarestrup F. 2003. Susceptibility of Escherichia coli and Enterococcus faecium isolated from pigs and broiler chickens to tetracycline degradation products and distribution of tetracycline resistance determinants in E. coli from food animals. Veterinary Microbiology. 95: 91-101. 